\title{
EFFECTS OF RADIATION AND ECKERT NUMBER ON MHD FLOW WITH HEAT TRANSFER RATE NEAR A STAGNATION POINT OVER A NON-LINEAR VERTICAL STRETCHING SHEET
}

\author{
O.J. FENUGA* \\ Department of Mathematics, University of Lagos \\ Akoka, Lagos, NIGERIA \\ E-mail: ofenuga@unilag.edu.ng \\ A.R. HASSAN \\ Department of Mathematics, Tai Solarin University of Education \\ Ogun State, NIGERIA \\ E-mail: anthonyhassan72@yahoo.co.uk \\ P.O. OLANREWAJU \\ Department of Mathematics and Statistics, Federal University \\ Wukari, TarabaState, NIGERIA \\ E-mail: oladapo_anu@yahoo.ie
}

\begin{abstract}
This work investigates the effects of radiation and Eckert number on an MHD flow with heat transfer rate near a stagnation-point region over a nonlinear vertical stretching sheet. Using a similarity transformation, the governing equations are transformed into a system of ordinary differential equations which are solved numerically using the sixth order Runge-Kutta method with shooting technique. Tabular and graphical results are provided to examine the physical nature of the problem. Heat transfer rate at the surface decreases with radiation, Eckert number and as radiation increases, the flow temperature also increases for velocity ratio parameters $\varepsilon<1$ and $\varepsilon>1$.
\end{abstract}

Key words: MHD flow, heat and mass transfer, radiation; Eckert number stagnation - point, non-linear vertical stretching sheet.

\section{Introduction}

Magnetohydromagnetic flow over a vertical flat plate is an important phenomenon in fluid mechanics because of its applications in engineering and industries including magnetohydynamic power generators, magnetohydrodynamic pumps, nuclear reactors, aerodynamics heating, electrostatic precipitation, polymer technology, petroleum industry, purification of crude oil, fluid droplets and sprays; biological problems like blood flow problems. Stagnation-point flow and heat transfer on a stretching sheet arise in practical applications like cooling of electronic devices and nuclear reactors, polymer extrusion, drawing of plastic sheets, etc. The study of magnetohydrodynamic flow near a stagnation-point flow on a stretching sheet has attracted the interest of many researchers in recent years. Alli et al. [1] studied a steady laminar, MHD mixed convection stagnation point flow of an incompressible fluid over a vertical stretching sheet using an implicit finite difference scheme. Akyildiz and Siginer [2] used the Galerkin- Legendre spectral method for the velocity and boundary layer of a flow and heat transfer over a nonlinearly stretching sheet. Asraf et al. [3], Dhanai et al. [4] and Mabood et al. [5] analyzed the boundary layer flow and heat transfer on a nonlinearly

\footnotetext{
* To whom correspondence should be addressed
} 
shrinking/stretching sheet immersed in a nanofluid. Akyildiz et al. [6] studied the similarity solution of the boundary layer equations for a nonlinearly stretching sheet. Das et al. [7] and Makinde et al. [8] investigated the buoyancy effects on an MHD stagnation point flow and heat transfer of a nanofluid past a convectively heated stretching/shrinking sheet. Makinde [9] investigated the heat and mass transfer of an MHD mixed convection stagnation point flow towards a vertical plate embedded in a highly porous medium with radiation and internal heat generation. Ishak et al. [10] studied a steady, two dimensional, MHD stagnation point flow towards a stretching sheet with variable surface temperature using a finite difference scheme known as KellerBox method. Ishak et al. [11] studied a two dimensional NHD flow of a viscous, incompressible and electrically conducting fluid over a stretching vertical surface with constant wall temperature using the Kellerbox method. Also, Khan et al. [12], investigated viscous dissipation effect on an MHD stagnation point Ferro fluid flow and heat transfer towards a stretching sheet. The work by Shen et al. [13] studied the problem of an MHD mixed convection stagnation-point flow on the nonlinearly vertical stretching sheet in the presence of buoyancy force, suction/injection parameters and boundary slip using the homotopy analysis method. Shateyi and Makinde [14] investigated the effects of viscous dissipation on a hydromagnetic stagnation-point flow towards a radially stretching convectively heated disk. Shateyi and Marewo [15] studied the MHD mixed convection stagnation-point flow and heat transfer of an incompressible viscous fluid over a vertical stretching sheet.

This work extends the work of Shen et al. [13] by considering the effects of the radiation parameter and Eckert number on an MHD flow with heat transfer rate near a stagnation point on a nonlinear vertical stretching sheet.

\section{Materials and method}

This work considers a steady, MHD, two-dimensional viscous, incompressible, electrically conducting flow near a stagnation point over a nonlinear vertical stretching sheet with the radiation parameter and Eckert number. The flow is confined to the region $y \geq 0$, where $y$ is the coordinate measured normal to the stretching sheet. The fluid is considered to be influenced by a transverse uniform magnetic field $B$, normal to the surface $y=0$. The flow model along with the coordinate system is shown in the figure below.

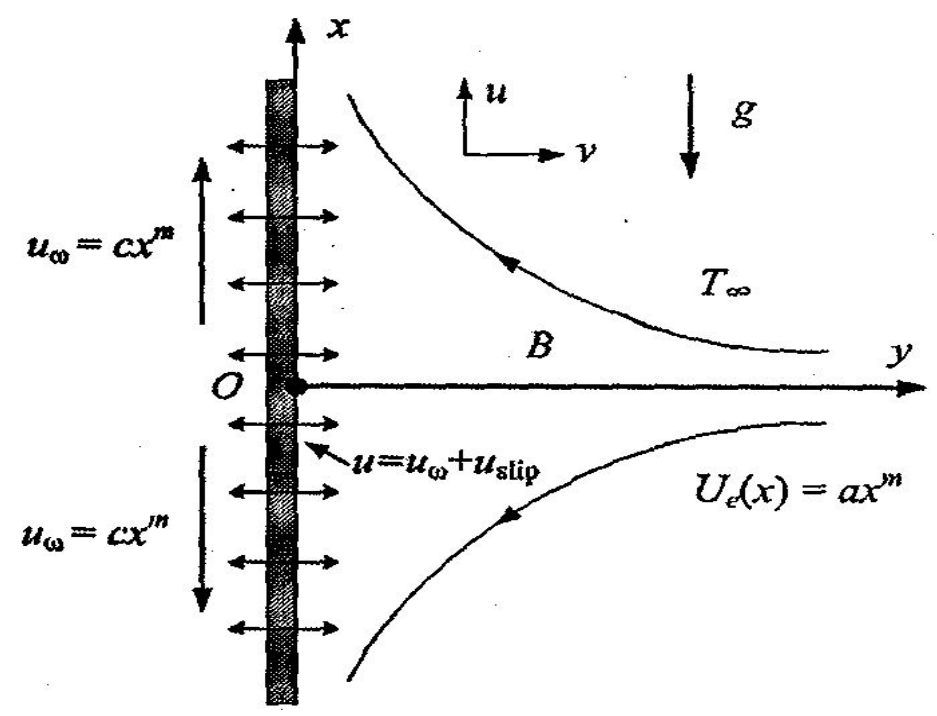

Fig.1. Physical model and coordinate system.

It is assumed that the sheet stretches with velocity $u_{w}(x)=c x^{m}$ and the external velocity is prescribed as $u_{e}(x)=a x^{m}$ where $a$ and $c$ are positive constants. The constant $m$ is the nonlinearity parameter with $m=1$ 
for the linear case and $m \neq 1$ for the nonlinear case. Under the boundary layer approximation, the basic continuity, momentum and energy equations describing the flow are

$$
\begin{aligned}
& \frac{\partial u}{\partial x}+\frac{\partial v}{\partial y}=0 \\
& u \frac{\partial u}{\partial x}+v \frac{\partial u}{\partial y}=u_{e} \frac{d u_{e}}{d x}+v \frac{\partial^{2} u}{\partial y^{2}}+\frac{\sigma B^{2}(x)}{\rho}\left(u_{e}-u\right)+g \beta\left(T-T_{\infty}\right) \\
& c_{p}\left(u \frac{\partial T}{\partial x}+v \frac{\partial T}{\partial y}\right)=\frac{\partial^{2} T}{\partial y^{2}}-\frac{\partial q_{r}}{\partial y}+\mu\left(\frac{\partial u}{\partial y}\right)^{2}
\end{aligned}
$$

where $u$ and $v$ are the velocity components in the $x$ and $y$ directions, $v$ is the kinematic viscosity, $u_{e}$ is the free stream or external velocity, $\rho$ is the fluid density, $\sigma$ is the electrical conductivity, $B(x)$ is the transverse magnetic field, $g$ is the acceleration due to gravity, $\beta$ is the thermal expansion coefficient, $T$ is the fluid temperature, $c_{p}$ is the specific heat at constant pressure, $\kappa$ is the thermal conductivity of the fluid under consideration, $q_{r}$ is the radiative heat flux and $\mu$ is the dynamic viscosity.

The relevant boundary conditions are

$$
\begin{aligned}
& u=u_{w}(x)+\frac{2-\sigma_{v}}{\sigma_{v}} \lambda_{0} \frac{\partial u}{\partial y}, \quad v=v_{w}(x), \quad \frac{\partial T}{\partial y}=-\frac{q_{w}(x)}{k} \quad \text { at } \quad y=0, \\
& u \rightarrow u_{e}(x), \quad T \rightarrow T_{\infty} \quad \text { as } \quad y \rightarrow \infty
\end{aligned}
$$

where $\sigma_{v}$ is the tangential momentum accommodation coefficient, $\lambda_{0}$ is the mean free path, $v_{w}(x)$ is the suction (or injection) velocity, $\kappa$ is the thermal conductivity and $q_{w}(x)$ is the surface heat flux, $\sigma$ is the electrical conductivity.

We introduce the following similarity variables in the transformation

$$
\eta=y \sqrt{\left(\frac{a}{v}\right)} x^{\frac{(m-1)}{2}}, \quad \psi=\sqrt{a v} x^{\frac{(m+1)}{2} f(\eta),} \text { and } \quad \theta=\sqrt{\left(\frac{a}{v}\right)} \frac{k\left(T-T_{\infty}\right)}{q_{0} x^{2 m-1}}
$$

where $\psi$ is the stream function. Equation (2.1) is satisfied by introducing $\psi$ such that

$$
u=\frac{\partial \psi}{\partial y} \quad \text { and } \quad v=-\frac{\partial \psi}{\partial x}
$$

Using the similarity variables in Eq.(2.6), the $x$ and $y$ velocity components are given as

$$
u=a x^{m} f^{\prime}(\eta)=u_{e} f^{\prime}(\eta), \quad v=-\sqrt{a v} x^{\frac{(m-1)}{2}}\left[\left(\frac{m+1}{2}\right) f(\eta)+\left(\frac{m-1}{2}\right) \eta f^{\prime}(\eta)\right]
$$

To obtain similarity solutions, $B(x), v_{x}(x)$ and $q_{w}(x)$ are taken as 


$$
B(x)=B_{o} x^{\frac{m-1}{2}}, v_{w}=-\frac{\sqrt{a v(m+1)}}{2} x^{\frac{m-1}{2}} S, q_{w}(x)=q_{0} x^{\frac{5 m-3}{2}}
$$

where $B_{0}, S$ and $q_{0}$ are constants. It should be noted that $S>0$ corresponds to injection and $S<0$ corresponds to suction. Substituting Eq.(2.6) into Eqs (2.2) and (2.3), the following nonlinear ordinary differential equations are obtained

$$
\begin{aligned}
& f^{\prime \prime \prime}+\left(\frac{M+1}{2}\right) f^{\prime \prime}+m\left(1-f^{\prime 2}\right)+M\left(1-f^{\prime}\right)+\lambda \theta=0, \\
& \frac{1}{\operatorname{Pr}}\left(1+\frac{4}{3} R d\right) \theta^{\prime \prime}-\left(\frac{m+1}{2}\right) f \theta^{\prime}-(2 m-1) f^{\prime} \theta+\operatorname{Ec}\left(f^{\prime \prime}\right)^{2} \theta=0 .
\end{aligned}
$$

Subject to the boundary conditions (2.12) and (2.13) below

$$
\begin{aligned}
& f(0)=S, \quad f^{\prime}(0)=\epsilon+f^{\prime \prime}(0), \quad \theta^{\prime}(0)=-1, \\
& f^{\prime}(\infty) \rightarrow 1, \quad \theta(\infty) \rightarrow 0, \quad f(\infty) \rightarrow 0 \quad \text { as } \quad \eta \rightarrow \infty
\end{aligned}
$$

where $m$ is the non-linearity parameter, $M$ is the magnetic parameter, $\lambda$ is the mixed convention parameter, $\varepsilon$ is the velocity ratio parameter, $\operatorname{Pr}$ is the Prandtl number, $R d$ is the radiation parameter, Ec is the Eckert number. Note that $R d=\mathrm{Ec}=0$ correspond to the work of Shen et al. (2015).

The skin friction coefficient $C_{f}$ and the local Nusselt number $\mathrm{Nu}_{x}$ are defined as $C_{f}=\frac{T_{w}(x)}{\rho u_{e}^{2}}$ and $\mathrm{Nu}_{x}=\frac{x q_{w}(x)}{k\left(T_{w}-T_{\infty}\right)^{\prime}}$ respectively, where the surface stress $T_{w}(x)=\mu\left(\frac{\partial u}{\partial y}\right)_{y=0}$ and $q_{w}(x)$ is the wall heat flux given by Eq.(2.9). Similarity variables (2.6) are also used to obtain

$$
\operatorname{Re}_{x}^{\frac{1}{2}} C_{f}=f^{\prime \prime}(0) \quad \text { and } \quad \operatorname{Re}_{x}^{-\frac{1}{2}} \mathrm{Nu}_{z}=\frac{1}{\theta(0)} .
$$

Solving the coupled non linear differential Eqs (2.10), (2.11) together with the boundary conditions (2.12) and (2.13) numerically by using the sixth order Runge-Kutta method with shooting technique for some values of the thermo physical parameters involved in the present problem, some graphical results are obtained and discussed in section 3 below.

\section{Results and discussion}

From the tabular results, Tabs 1 and 2 it follows that the values of skin friction $f^{\prime \prime}(0)$ and the heat transfer rate at the surface $\frac{1}{\theta(\theta)}$ decrease with radiation parameter $(R d)$ and Eckert number $(\mathrm{Ec})$. It is also observed that the values of $f^{\prime \prime}(0)$ are negative for the velocity ratio parameter $\varepsilon>1$ which indicates that the sheet exerts a drag force on the fluid. For the velocity ratio parameter $\varepsilon<1$, the values of $f^{\prime \prime}(0)$ are positive which indicates that the formation of the boundary layer depends solely on the stretching sheet. However, the 
heat transfer rate at the surface $\frac{1}{\theta(0)}$ increases positively with the nonlinearity parameter $m$ which means that the heat is transferred from the hot sheet to the cold fluid. In Figs 2-3, larger values of the radiation parameter $R d$ give larger heat energy into the flow field leading to a rise in temperature. In addition, the flow has a boundary layer structure, when the velocity ratio parameter $\varepsilon<1$ and the nonlinearity parameter $m \geq 1$ but the stretching velocity $u_{w}(x)$ of the surface exceeds the velocity $u_{e}(x)$ of the external stream when $\varepsilon>1$ and $m \geq 1$. In Fig.2, the thickness of the velocity boundary layer decreases with $R d$ for both cases of velocity ratio parameters $\varepsilon=0.1<1$ and $\varepsilon=2>1$.

Table 1. Computation showing values of $f^{\prime \prime}(0)$ and $\frac{1}{\theta(0)}$ with $m, M, \operatorname{Pr}, \operatorname{Rd}, \mathrm{Ec}, S$ and $\varepsilon$ as prescribed parameters when $\varepsilon<1$.

\begin{tabular}{|c|c|c|c|c|c|c|c|c|c|c|}
\hline$m$ & $M$ & $\lambda$ & $\operatorname{Pr}$ & $R d$ & Ec & $S$ & $\varepsilon$ & $\delta$ & $f^{\prime \prime}(0)$ & $\frac{1}{\theta(0)}$ \\
\hline 0.6 & 1.0 & -1.0 & 0.72 & 0.1 & 0.1 & 0.5 & 0.1 & 0.5 & 0.43324755 & 0.68412902 \\
\hline 0.8 & 1.0 & -1.0 & 0.72 & 0.1 & 0.1 & 0.5 & 0.1 & 0.5 & 0.60714450 & 0.86084261 \\
\hline 1.0 & 1.0 & -1.0 & 0.72 & 0.1 & 0.1 & 0.5 & 0.1 & 0.5 & 0.71261082 & 1.01790207 \\
\hline 2.0 & 1.0 & -1.0 & 0.72 & 0.1 & 0.1 & 0.5 & 0.1 & 0.5 & 0.95718484 & 1.63433990 \\
\hline 2.0 & 0.0 & -1.0 & 0.72 & 0.1 & 0.1 & 0.5 & 0.1 & 0.5 & 0.90576027 & 1.61412314 \\
\hline 2.0 & 1.0 & -1.0 & 0.72 & 0.1 & 0.1 & 0.5 & 0.1 & 0.5 & 0.95726039 & 1.63487739 \\
\hline 2.0 & 3.0 & -1.0 & 0.72 & 0.1 & 0.1 & 0.5 & 0.1 & 0.5 & 1.03306651 & 1.66398763 \\
\hline 2.0 & 5.0 & -1.0 & 0.72 & 0.1 & 0.1 & 0.5 & 0.1 & 0.5 & 1.08796821 & 1.68396574 \\
\hline 2.0 & 1.0 & -2.0 & 0.72 & 0.1 & 0.1 & 0.5 & 0.1 & 0.5 & 0.87744021 & 1.60540587 \\
\hline 2.0 & 1.0 & -1.0 & 0.72 & 0.1 & 0.1 & 0.5 & 0.1 & 0.5 & 0.95778612 & 1.63865204 \\
\hline 2.0 & 1.0 & 0.0 & 0.72 & 0.1 & 0.1 & 0.5 & 0.1 & 0.5 & 1.03201271 & 1.66863926 \\
\hline 2.0 & 1.0 & 1.0 & 0.72 & 0.1 & 0.1 & 0.5 & 0.1 & 0.5 & 1.10131988 & 1.69604385 \\
\hline 2.0 & 1.0 & 2.0 & 0.72 & 0.1 & 0.1 & 0.5 & 0.1 & 0.5 & 1.16656018 & 1.72134146 \\
\hline 2.0 & 1.0 & -1.0 & 0.72 & 0.1 & 0.1 & 0.5 & 0.1 & 0.5 & 0.95718484 & 1.6343399 \\
\hline 2.0 & 1.0 & -1.0 & 1 & 0.1 & 0.1 & 0.5 & 0.1 & 0.5 & 0.97649466 & 1.98069122 \\
\hline 2.0 & 1.0 & -1.0 & 3 & 0.1 & 0.1 & 0.5 & 0.1 & 0.5 & 1.01382189 & 3.92349716 \\
\hline 2.0 & 1.0 & -1.0 & 5 & 0.1 & 0.1 & 0.5 & 0.1 & 0.5 & 1.02199885 & 5.55620749 \\
\hline 2.0 & 1.0 & -1.0 & 0.72 & 0 & 0.1 & 0.5 & 0.1 & 0.5 & 0.96512313 & 1.75767413 \\
\hline 2.0 & 1.0 & -1.0 & 0.72 & 1 & 0.1 & 0.5 & 0.1 & 0.5 & 0.89392320 & 1.08441954 \\
\hline 2.0 & 1.0 & -1.0 & 0.72 & 3 & 0.1 & 0.5 & 0.1 & 0.5 & 0.78658728 & 0.72184243 \\
\hline 2.0 & 1.0 & -1.0 & 0.72 & 5 & 0.1 & 0.5 & 0.1 & 0.5 & 0.70912958 & 0.5903847 \\
\hline 2.0 & 1.0 & -1.0 & 0.72 & 0.1 & 0.0 & 0.5 & 0.1 & 0.5 & 0.95765482 & 1.64280403 \\
\hline 2.0 & 1.0 & -1.0 & 0.72 & 0.1 & 1.0 & 0.5 & 0.1 & 0.5 & 0.95268695 & 1.55774536 \\
\hline 2.0 & 1.0 & -1.0 & 0.72 & 0.1 & 3.0 & 0.5 & 0.1 & 0.5 & 0.94059360 & 1.38485403 \\
\hline 2.0 & 1.0 & -1.0 & 0.72 & 0.1 & 5.0 & 0.5 & 0.1 & 0.5 & 0.92443242 & 1.2083549 \\
\hline 2.0 & 1.0 & -1.0 & 0.72 & 0.1 & 0.1 & -1.0 & 0.1 & 0.5 & 0.53832521 & 0.72608092 \\
\hline 2.0 & 1.0 & -1.0 & 0.72 & 0.1 & 0.1 & -0.5 & 0.1 & 0.5 & 0.70838863 & 1.00907493 \\
\hline 2.0 & 1.0 & -1.0 & 0.72 & 0.1 & 0.1 & 0.0 & 0.1 & 0.5 & 0.84383107 & 1.31047035 \\
\hline 2.0 & 1.0 & -1.0 & 0.72 & 0.1 & 0.1 & 0.5 & 0.1 & 0.5 & 0.95726039 & 1.63487739 \\
\hline 2.0 & 1.0 & -1.0 & 0.72 & 0.1 & 0.1 & 1.0 & 0.1 & 0.5 & 1.05290596 & 1.98108745 \\
\hline 2.0 & 1.0 & -1.0 & 0.72 & 0.1 & 0.1 & 0.5 & 0.1 & 0 & 2.00129219 & 1.37106676 \\
\hline 2.0 & 1.0 & -1.0 & 0.72 & 0.1 & 0.1 & 0.5 & 0.1 & 0.5 & 0.95718484 & 1.6343399 \\
\hline 2.0 & 1.0 & -1.0 & 0.72 & 0.1 & 0.1 & 0.5 & 0.1 & 1 & 0.61605802 & 1.7004017 \\
\hline 2.0 & 1.0 & -1.0 & 0.72 & 0.1 & 0.1 & 0.5 & 0.1 & 3 & 0.25197991 & 1.76350408 \\
\hline
\end{tabular}


Table 2. Computation showing values of $f^{\prime \prime}(0)$ and $\frac{1}{\theta(0)}$ with $m, M, \operatorname{Pr}, \operatorname{Rd}, \mathrm{Ec}, S$ and $\varepsilon$ as prescribed parameters when $\varepsilon>1$.

\begin{tabular}{|c|c|c|c|c|c|c|c|c|c|c|}
\hline$M$ & $M$ & $\lambda$ & $\operatorname{Pr}$ & $R d$ & Ec & $S$ & $\varepsilon$ & $\delta$ & $f^{\prime \prime}(0)$ & $\frac{1}{\theta(0)}$ \\
\hline 0.6 & 1.0 & -1.0 & 0.72 & 0.1 & 0.1 & 0.5 & 2 & 0.5 & -1.23320442 & 0.84676021 \\
\hline 0.8 & 1.0 & -1.0 & 0.72 & 0.1 & 0.1 & 0.5 & 2 & 0.5 & -1.19285255 & 1.06868916 \\
\hline 1.0 & 1.0 & -1.0 & 0.72 & 0.1 & 0.1 & 0.5 & 2 & 0.5 & -1.18629736 & 1.25772956 \\
\hline 2.0 & 1.0 & -1.0 & 0.72 & 0.1 & 0.1 & 0.5 & 2 & 0.5 & -1.24453308 & 1.96339134 \\
\hline 2.0 & 0.0 & -1.0 & 0.72 & 0.1 & 0.1 & 0.5 & 2 & 0.5 & -1.21621884 & 1.97310656 \\
\hline 2.0 & 1.0 & -1.0 & 0.72 & 0.1 & 0.1 & 0.5 & 2 & 0.5 & -1.24450448 & 1.96372378 \\
\hline 2.0 & 3.0 & -1.0 & 0.72 & 0.1 & 0.1 & 0.5 & 2 & 0.5 & -1.29106348 & 1.94878452 \\
\hline 2.0 & 5.0 & -1.0 & 0.72 & 0.1 & 0.1 & 0.5 & 2 & 0.5 & -1.32830397 & 1.93732309 \\
\hline 2.0 & 1.0 & -2.0 & 0.72 & 0.1 & 0.1 & 0.5 & 2 & 0.5 & -1.29387864 & 1.94769676 \\
\hline 2.0 & 1.0 & -1.0 & 0.72 & 0.1 & 0.1 & 0.5 & 2 & 0.5 & -1.24430614 & 1.96625134 \\
\hline 2.0 & 1.0 & 0.0 & 0.72 & 0.1 & 0.1 & 0.5 & 2 & 0.5 & -1.19659273 & 1.98386222 \\
\hline 2.0 & 1.0 & 1.0 & 0.72 & 0.1 & 0.1 & 0.5 & 2 & 0.5 & -1.15054158 & 2.00063683 \\
\hline 2.0 & 1.0 & 2.0 & 0.72 & 0.1 & 0.1 & 0.5 & 2 & 0.5 & -1.10598854 & 2.01666415 \\
\hline 2.0 & 1.0 & -1.0 & 0.72 & 0.1 & 0.1 & 0.5 & 2 & 0.5 & -1.24453308 & 1.96339134 \\
\hline 2.0 & 1.0 & -1.0 & 1 & 0.1 & 0.1 & 0.5 & 2 & 0.5 & -1.23167007 & 2.39532219 \\
\hline 2.0 & 1.0 & -1.0 & 3 & 0.1 & 0.1 & 0.5 & 2 & 0.5 & -1.20772220 & 4.78056534 \\
\hline 2.0 & 1.0 & -1.0 & 5 & 0.1 & 0.1 & 0.5 & 2 & 0.5 & -1.20271982 & 6.72050059 \\
\hline 2.0 & 1.0 & -1.0 & 0.72 & 0 & 0.1 & 0.5 & 2 & 0.5 & -1.23921710 & 2.11724772 \\
\hline 2.0 & 1.0 & -1.0 & 0.72 & 1 & 0.1 & 0.5 & 2 & 0.5 & -1.28784764 & 1.27909914 \\
\hline 2.0 & 1.0 & -1.0 & 0.72 & 3 & 0.1 & 0.5 & 2 & 0.5 & -1.36383125 & 0.83105127 \\
\hline 2.0 & 1.0 & -1.0 & 0.72 & 5 & 0.1 & 0.5 & 2 & 0.5 & -1.42050867 & 0.66816274 \\
\hline 2.0 & 1.0 & -1.0 & 0.72 & 0.1 & 0.0 & 0.5 & 2 & 0.5 & -1.24422719 & 1.97389495 \\
\hline 2.0 & 1.0 & -1.0 & 0.72 & 0.1 & 1.0 & 0.5 & 2 & 0.5 & -1.24747310 & 1.86791895 \\
\hline 2.0 & 1.0 & -1.0 & 0.72 & 0.1 & 3.0 & 0.5 & 2 & 0.5 & -1.25551243 & 1.64905882 \\
\hline 2.0 & 1.0 & -1.0 & 0.72 & 0.1 & 5.0 & 0.5 & 2 & 0.5 & -1.26667252 & 1.41883920 \\
\hline 2.0 & 1.0 & -1.0 & 0.72 & 0.1 & 0.1 & -1.0 & 2 & 0.5 & -1.06207493 & 1.28855164 \\
\hline 2.0 & 1.0 & -1.0 & 0.72 & 0.1 & 0.1 & -0.5 & 2 & 0.5 & -1.12266016 & 1.48009367 \\
\hline 2.0 & 1.0 & -1.0 & 0.72 & 0.1 & 0.1 & 0.0 & 2 & 0.5 & -1.18401357 & 1.70517250 \\
\hline 2.0 & 1.0 & -1.0 & 0.72 & 0.1 & 0.1 & 0.5 & 2 & 0.5 & -1.24450448 & 1.96372378 \\
\hline 2.0 & 1.0 & -1.0 & 0.72 & 0.1 & 0.1 & 1.0 & 2 & 0.5 & -1.30259268 & 2.25397393 \\
\hline 2.0 & 1.0 & -1.0 & 0.72 & 0.1 & 0.1 & 0.5 & 2 & 0 & -3.28425998 & 2.12988034 \\
\hline 2.0 & 1.0 & -1.0 & 0.72 & 0.1 & 0.1 & 0.5 & 2 & 0.5 & -1.24453308 & 1.96339134 \\
\hline 2.0 & 1.0 & -1.0 & 0.72 & 0.1 & 0.1 & 0.5 & 2 & 1 & -0.77753047 & 1.90968646 \\
\hline 2.0 & 1.0 & -1.0 & 0.72 & 0.1 & 0.1 & 0.5 & 2 & 3 & -0.31278848 & 1.84891810 \\
\hline
\end{tabular}




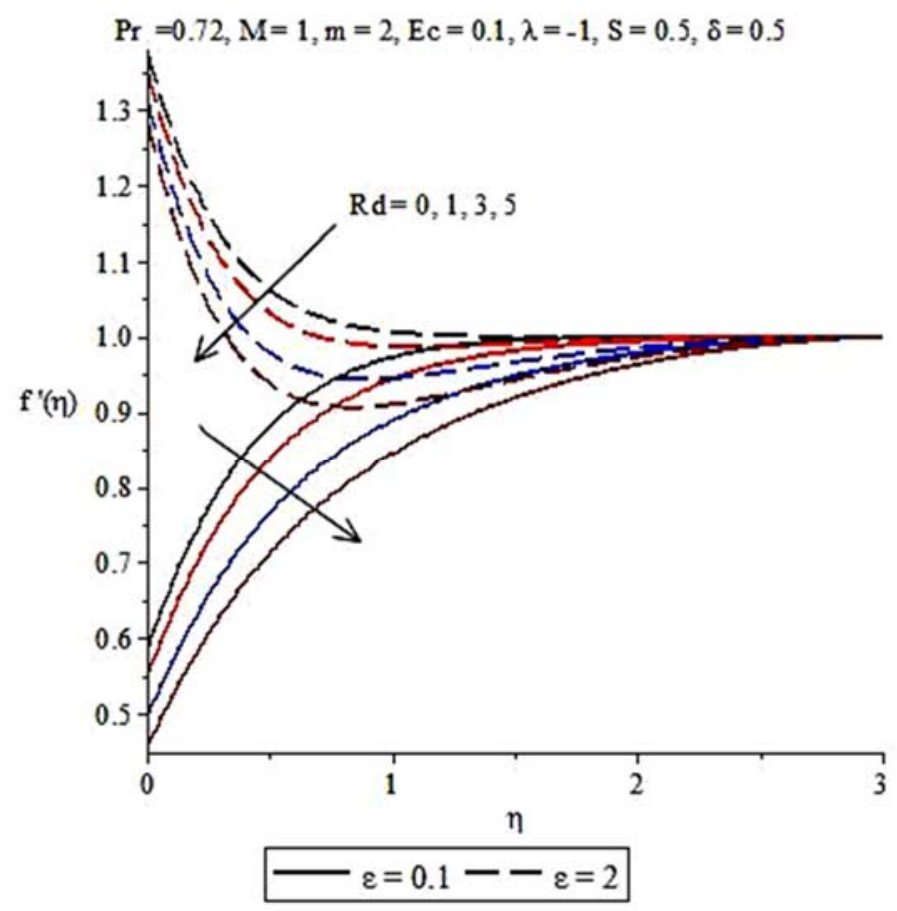

Fig.2. Velocity profile $f^{\prime}(\eta)$ for different values of $\varepsilon$.

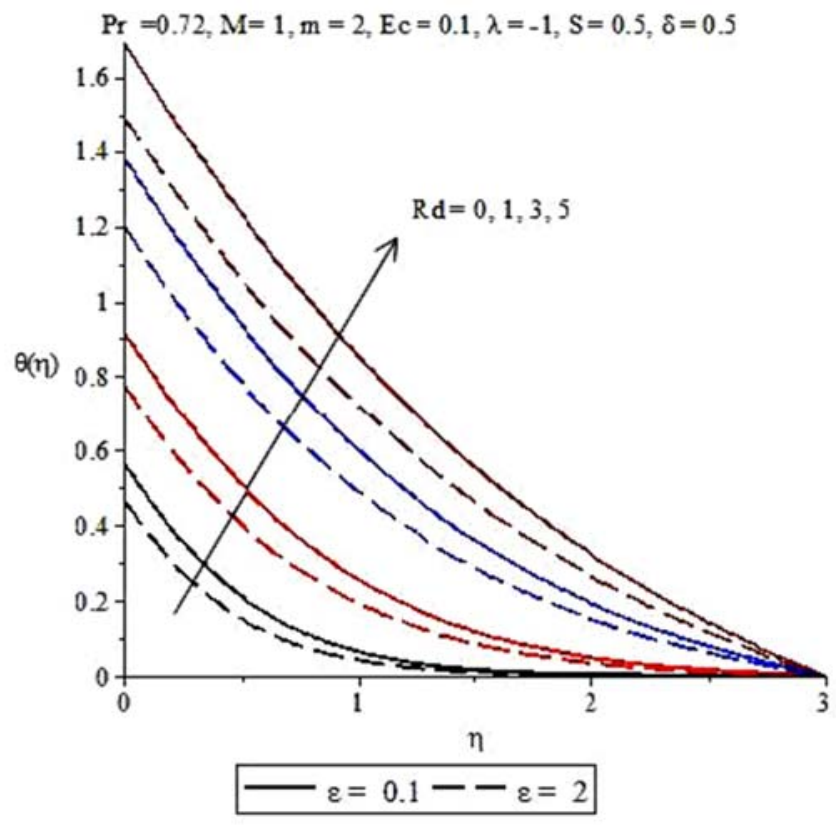

Fig.3. Temperature profile $\theta(\eta)$ for different values of $R d$.

Figures 4-5 show the effects of the Eckert number Ec on the velocity and temperature profiles. In Fig.4, it is observed that the thickness of the velocity boundary layer decreases with the Eckert number Ec for both cases of $\varepsilon=0.1<1$ and $\varepsilon=2>1$. The velocity field $f^{\prime}(\eta)$ is always an increasing function of Ec for the two cases. Figure 5 shows that an increase in Ec corresponds to an increase in the temperature and the thermal 
boundary layer thickness. So, the wall temperature $\theta(0)$ also increases with increasing Ec, which means that the heat transfer rate $1 / \theta(0)$ decreases as Ec increases.

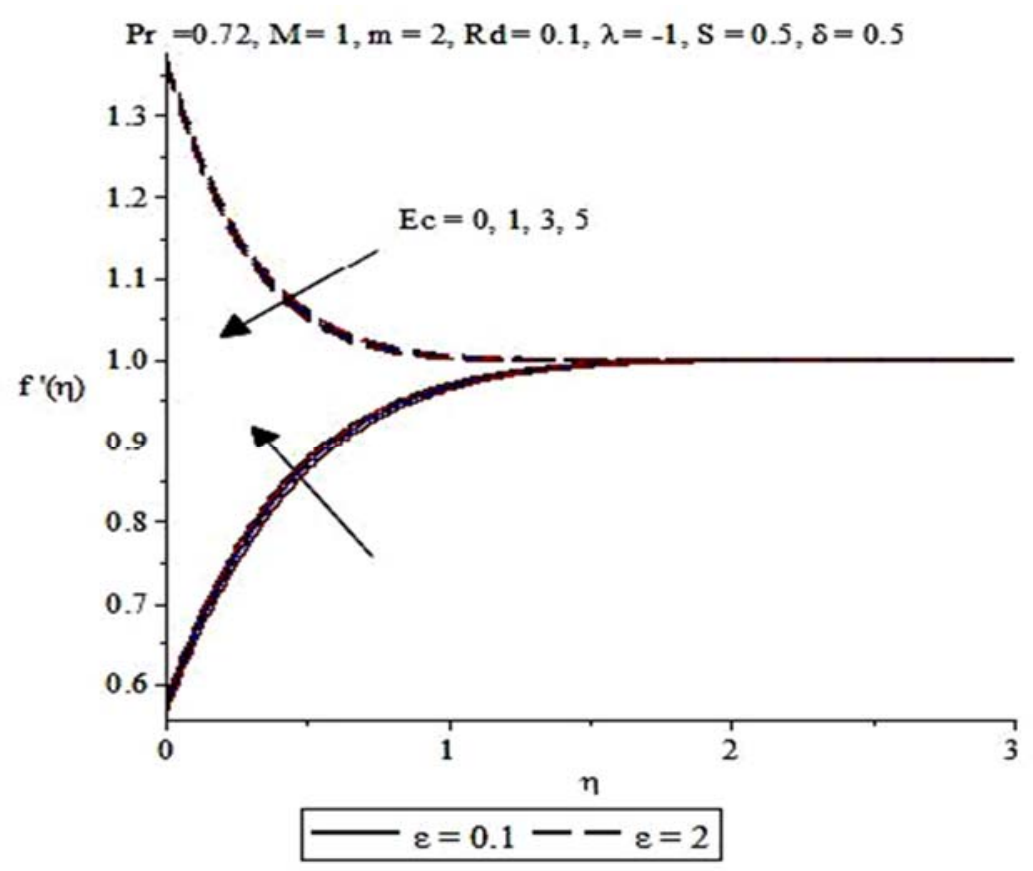

Fig.4. Velocity profile $f^{\prime}(\eta)$ for different values of Ec.

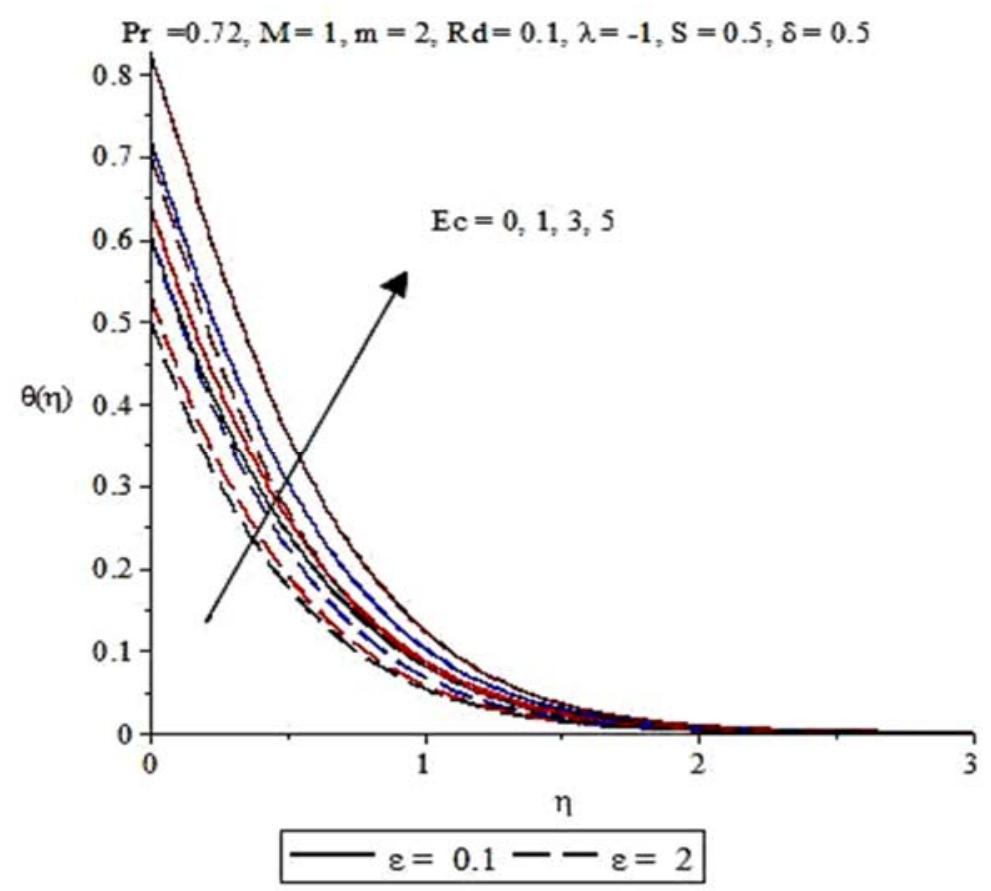

Fig.5. Temperature profile $\theta(\eta)$ for different values of Ec. 


\section{Conclusion}

This work considers the effects of radiation and the Eckert number on an MHD flow with heat transfer rate near a stagnation point on a nonlinear vertical stretching sheet using the sixth order Runge Kutta method with shooting technique. The tabular and graphical results show that:

(i) The skin friction $f^{\prime \prime}(0)$ and the local Nusselt number $\frac{1}{\theta(0)}$ which represent the heat transfer rate decrease as the radiation parameter $R d$ and Eckert number Ec decrease.

(ii) The skin friction $f^{\prime \prime}(0)$ decreases when the velocity ratio parameter $\varepsilon>1$ which indicates that the sheet exerts a drag force on the fluid.

(iii) The skin friction $f^{\prime \prime}(0)$ increases when the velocity ratio parameter $\varepsilon<1$ which indicates that the formation of the boundary layer depends solely on the stretching sheet.

(iv) The larger the value of the radiation parameter $\mathrm{Rd}$, the larger the value of radiative heat energy into the flow field which causes a rise in temperature.

(v) The thickness of the velocity boundary layer decreases with the radiation parameter $R d$ for the velocity ratio parameter $\varepsilon<1$ and $\varepsilon>1$

(vi) An increase in the radiation parameter $R d$ will increase the temperature and thermal boundary layer thickness.

(vii) Wall temperature $\theta(0)$ increases with an increase in the radiation parameter $R d$ but the heat transfer rate $\frac{1}{\theta(0)}$ decreases as the radiation parameter $R d$ increases.

\section{Nomenclature}

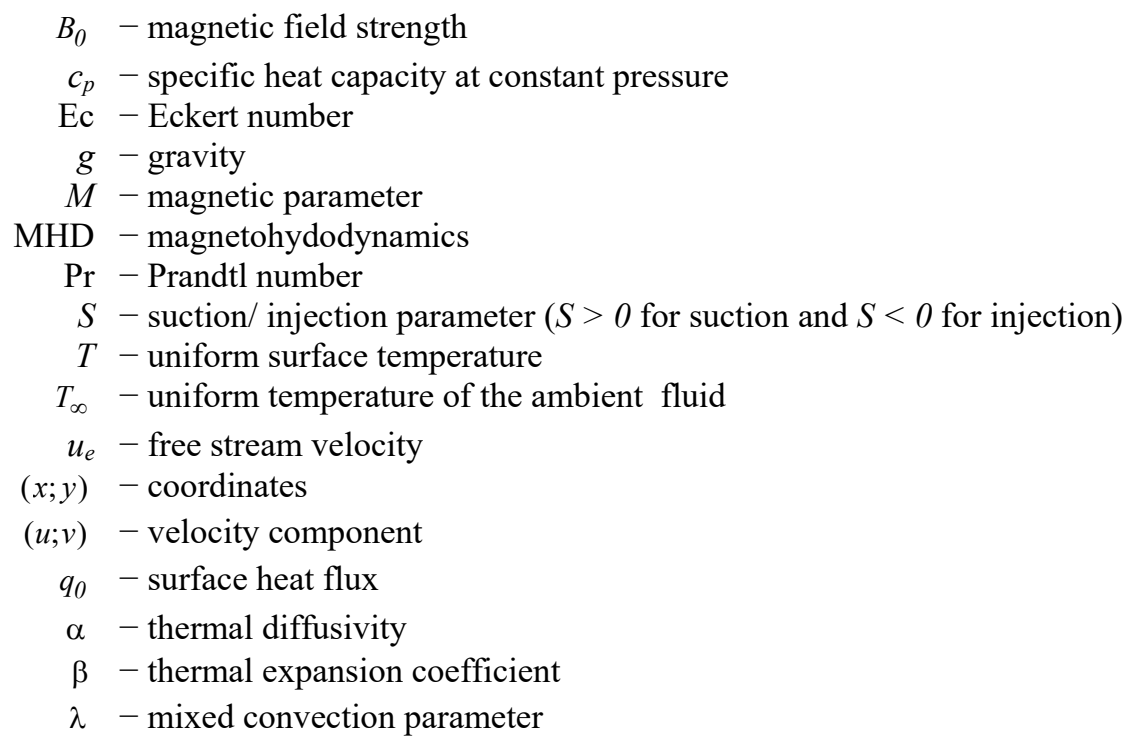

\section{Acknowledgment}

The authors appreciate the referees comments and their useful suggestions which improvedg the quality of the paper. 


\section{References}

[1] Ali F.M., Nazar R., Arin N.N. and Pop I. (2014): Mixed convection stagnation-point flow on vertical stretching sheet with external magnetic field. Appl. Math. Mech., vol.35, No.2, pp.155-166.

[2] Akyildiz F.T. and Siginer D.A. (2010): Galerkin-Legendre spectral method for the velocity and thermal boundary layers over a non-linearly stretching sheet. Nonlinear Anal., Real World Appl., vol.11, No.2, pp.735-741.

[3] Ashraf M.B., Hayat T. and Alsaedi A. (2015): Three-dimensional flow of Eyring-Powell nanofluid by convectively heated exponentially stretching sheet. Eur. Phys. J. Plus, vol.130, No.1, pp.1-16.

[4] Dhanai R. Rana and Kumar L. (2015): Multiple solutions of MHD boundary layer flow and heat transfer behavior of nanofluids induced by a power-law stretching/shrinking permeable sheet with viscous dissipation. Powder Technol., vol.273, pp.62-70.

[5] Mabood F., Khan W.A. and Ismail A.M. (2015): MHD boundary layer flow and heat transfer of nanofluids over a nonlinear stretching sheet: a numerical study. J. Magn. Magn. Mater., vol.374, pp.569-576.

[6] Akyildiz F.T., Siginer D.A., Vajravelu K., Cannon J.R. and Van Gorder R.A. (2010): Similarity solutions of the boundary layer equations for a nonlinearly stretching sheet. Math. Methods Appl. Sci., vol.33, No.5, pp.601-606.

[7] Das S., Jana R.N. and Makinde O.D. (2014): MHD boundary layer slip flow and heat transfer of nanofluid past a vertical stretching sheet with non-uniform heat generation/absorption. Int. J. Nanosci., vol.13, No.3, pp.1450019.

[8] Makinde O.D., Khan A.H. and Khan Z.H. (2013): Buoyancy effects on MHD stagnation point flow and heat transfer of a nanofluid past a convectively heated stretching/shrinking sheet. Int. J. Heat Mass Transf., vol.62, No.526-533.

[9] Makinde O.D. (2012): Heat and mass transfer by MHD mixed convection stagnation point flow toward a vertical plate embedded in a highly porous medium with radiation and internal heat generation. Meccanica, vol.47, pp.1173-1184.

[10] Ishak A., Jafar K., Nazar R. and Pop I. (2009): MHD stagnation point flow towards a stretching sheet. Physica A, vol.388, No.13, pp.3377-3383.

[11] Ishak A., Nazar R. and Pop I. (2010): MHD mixed convection boundary layer flow towards a stretching vertical surface with constant wall temperature. Int. J. Heat Mass Transf., vol.53, No.23-24, pp.5330-5334.

[12] Khan Z.H., Khan W.A., Qasim M. and Shah I.A. (2014): MHD stagnation point ferro fluid flow and heat transfer toward a stretching sheet. IEEE Trans. Nanotechnol., vol.13, No.1, pp.35-40.

[13] Shen M., Wang F. and Chen H. (2015): MHD Mixed Convection slip flow near stagnation-point on a nonlinearly vertical stretching sheet. Boundary value problem. Spinger open Journal, 78.

[14] Shateyi S. and Makinde O.D. (2013): Hydromagnetic stagnation-point flow towards a radially stretching convectively heated disk. Math. Problem in Engineering, Article ID 616947.

[15] Shateyi S. and Marewo G.T. (2014): Numerical analysis of unsteady MHD flow near a stagnation point of a twodimensional porous body with heat and mass transfer, thermal transfer and chemical reaction. Boundary Value Problem, 218.

Received: April 3, 2019

Revised: November 21, 2019 